EDITORIAL

\title{
The Diamod Tip.
}

\section{Jose Baeza-Noci}

Editor-in-chief, Journal of Ozone Therapy

\section{Әे OPEN ACCESS}

\section{Citation}

Baeza-Noci J. The Diamod Tip. J Ozone

Ther. 2020:4(5)

doi: $10.7203 / j 03 t .4 .5 .2020 .21363$

\section{Academic Editor}

Jose Baeza-Noci,

School of Medicine, Valencia

University, SPAIN

\section{Editor}

World Federation of Ozone Therapy,

Brescia, ITALY

\section{Received}

April 22, 2019

\section{Accepted}

July 23, 2019

\section{Published}

December 18, 2020

\section{Intellectual Property}

Baeza-Noci J.

This is an open access article distributed under the terms of the Creative Commons Attribution License (CC BY 4.0), which permits unrestricted use, distribution, and reproduction in any medium, provided the original author and source are credited.

\section{Authors information}

editor-in-chief@journalofozonetherapy.org

\section{EDITORIAL}

This issue 5 is devoted to spine diseases that can be treated or improved by using medical ozone. Dr. Alberto Alexandre compiled during 2015 and 2016 a number of papers from experienced authors in order to prepare a monographic issue but found a lot of difficulty in publishing it. I offered him our Journal to publish these scientific works and he agreed.

COVID-19 pandemic has produce a huge increase in publishing time for all journals but we finally have been able to produce this issue. Due to the delay in its publication, some papers have been published by their authors in other journals.

We are hardly working in issue 6 that will be opened for different topics and we are preparing issue 7 that we expect to be a monographic on dental applications.

All papers are welcomed! 